\title{
LA DANZA, ¿COMPRENSIÓN Y COMUNICACIÓN A TRAVÉS DEL CUERPO EN MOVIMIENTO?
}

\author{
Herminia Pagola Martínez \\ Universidad de La Rioja \\ herminia.pagola@unirioja.es
}

\begin{abstract}
RESUMEN: En el siguiente artículo presentamos un estudio del fenómeno de la danza humana considerada como expresión artística inherente al ser humano desde la antigüedad. Tras unas breves consideraciones históricas desarrollamos una perspectiva filosófica que toma como punto de partida la tradición hermenéutica y que plantea nuestros cuestionamientos de fondo sobre la danza y el arte. Continuamos analizando las últimas aportaciones hechas por la ciencia cognitiva y sus implicaciones y aplicaciones actuales en el ámbito de la danza como arte en movimiento. En la parte final, en base a los aspectos histórico, filosófico y cognitivo analizados volvemos a desarrollar una perspectiva filosófica, apoyándonos en buena medida en el enfoque de Eugenio Trías, que ofrece una visión de conjunto y nos permite argumentar los motivos que nos Ilevan a considerar la danza, al igual que el juego autónomo observado por un espectador (Gadamer), como metacomunicación.
\end{abstract}

Palabras clave: Danza, arte, comunicación, comprensión, metacomunicación, E. Trías.

\section{DANCE, ¿COMPREHENSION AND COMMUNICATION THROUGH BODIES IN MOTION?}

\begin{abstract}
The present article develops a theoretical analysis of human dance as an artistic expression inherent to the human being since ancient times. After some brief historical considerations, the article develops a philosophical perspective that takes as its starting point the hermeneutic tradition and raises fundamental questions about dance and art. There follows an analysis of the latest contributions made by cognitive science and its implications and current applications for dance as art in movement. At the end, on the basis of the historical, philosophical and cognitive aspects analyzed, and of Eugenio Trias's approach, we develop again a philosophical perspective which offers an overview of the
\end{abstract}


phenomenon and allows us to regard it -like the selfcontained game seen by a spectator (Gadamer) - as metacommunication.

Keywords: Dance, art, communication, comprehensión, metacommunication, E. Trías.

Recibido: 7 de Noviembre de 2016

Aceptado: 26 de Noviembre de 2016

\section{Introducción histórica}

Curt Sachs (1881-1959) en su obra Historia Universal de la Danza argumenta que desde los pueblos más primitivos de la antigüedad hasta hoy se han mantenido constantes dos motivaciones principales en la Humanidad a la hora de danzar: una, la búsqueda obligada de expresión motor-rítmica ante cualquier circunstancia inusitada; y dos, el logro de un estado extático a través de la misma ${ }^{1}$. Acorde con lo dicho por Sachs encontramos la definición de danza realizada por Stéphane Mallarmé (1842-1898): "La danza es un armonioso deslizarse subordinado a la música y al éxtasis" ${ }^{2}$. La expresión corporal motor-rítmica ha sido, por lo tanto, una necesidad para el hombre desde el principio como vehículo de salida o desahogo ante determinadas circunstancias y desde muy temprano el hombre ha buscado alcanzar un estado de éxtasis ${ }^{3}$ a través de la danza, según nos dice Sachs. Señala además que este estado de éxtasis "ha sido desarrollado primitivamente de forma involuntaria y forzada y originado en el frenesí y en el desorden neuropático llevado al extremo" ${ }^{\prime 4}$. Al menos en lo que a estos pueblos primitivos respecta, el método esencial para alcanzar este estado extático se basa en el golpe rítmico impreso a cada movimiento o secuencia de movimientos de la danza: "La moción rítmica ha sido así el creador y conductor de casi todo gesto extático de alguna significación para la vida humana" afirma Sachs. En referencia a estos pueblos, continúa explicando que este éxtasis Ileva aparejado un efectivo desahogo de la voluntad: "Los movimientos se ejecutan rítmicamente de manera automática, sin intervención del yo; la consciencia del yo desaparece completamente y se pierde en la consciencia primitiva" ${ }^{\prime \prime}$.

1. Sachs, C., Historia Universal de la Danza. Buenos Aires, Centurión, 1944, p. 27. Pese a que es una obra que está escrita a mitades del siglo pasado, todavía hoy, en nuestros días se trata de una de las referencias obligadas en este ámbito por ser una obra completa y exhaustiva, de las pocas que encontramos en el campo de la historia de esta disciplina.

2. Markessinis, A., Historia de la danza desde sus orígenes. L. D. Esteban Sanz Martier, Madrid, 1995, p. 15.

3. La primera acepción de la palabra éxtasis en el Diccionario de la R.A.E. hace referencia a un estado del alma caracterizado por una gran admiración y alegría.

4. Sachs, C., Historia Universal de la Danza, p. 34.

5. Sachs, C., Historia Universal de la Danza, p. 37. 
Desde la perspectiva histórica dibujada por Sachs, al menos en los pueblos primitivos, danzar implica una vez alcanzado el mencionado estado de éxtasis una pérdida de consciencia del yo, el cuerpo automatiza los movimientos a través de la repetición rítmica y éstos se ejecutan desde el inconsciente sin intervención de la voluntad y sin intencionalidad. Es probable por lo tanto que se trate de una cualidad inherente en mayor o menor medida a esta disciplina ya que como afirma Sachs y se refleja en la definición de Mallarmé, la búsqueda de este estado de alegría, ese estado de desahogo a través de la danza ha sido una constante desde la antigüedad hasta nuestros días ${ }^{6}$. En la actualidad, en la danza o baile modernos podemos asumir que se llega a alcanzar ese estado y que en algunos momentos se puede llegar a producir esa supuesta pérdida de consciencia del yo, como menciona Sachs, pero sin embargo, sabemos que el artista que baila sigue siendo de alguna manera consciente de su cuerpo y de su entorno (de la música, por ejemplo) para llevar a cabo con éxito su baile. ¿Qué nos dicen los profesionales e investigadores de la danza en nuestros días?

Sharon Chaiklin7 quien afirma que "hemos danzado desde que pusimos nuestros pies sobre la tierra" en el libro La vida es danza (2008) dice que en las antiguas comunidades tribales la danza era concebida como un medio de comunicación con los dioses y que a menudo, las estructuras de movimiento (que tomaron formas distintas en cada cultura) provocaron estados de trance ${ }^{8}$. Nos dice Chaiklin:

En el Lejano Oriente, las danzas han formado siempre parte de la vida religiosa y espiritual; (...) En el mundo occidental existía una creencia similar respecto a que el arte era una parte necesaria de la vida y que la danza tenía un poder mágico inmanente ${ }^{9}$.

Thomas Shack ${ }^{10}$ en el libro The Neurocognition of Dance (2010) hace en la introducción una importante aportación sobre qué es lo que le pasa a la persona que baila o que danza en un escenario:

6. Cabría analizar en qué medida o en qué grado se da esta cualidad dependiendo del tipo de danza, pero no desarrollamos aquí este tema que se contempla en buena medida en Sachs, C., Historia Universal de la Danza, espec. caps. 1 y 2 de la primera parte, pp. 21150.

7. Sharon Chaiklin es danza movimiento terapeuta y miembro fundador de la ADTA (American Dance Therapy Association) en 1966, así como presidenta de la misma entre 1968 y 1972. Discí pula cercana de Marian Chace, una de las pioneras en la estructuración de la danza y el movimien to como profesión terapéutica, actualmente es la Directora de la Fundación que lleva su nombre.

8. Wengrower, H. y Chaiklin, Sh. (coords.), La vida es danza. El arte y la ciencia de la Danza Movimiento Terapia. Barcelona, Gedisa, 2008, p. 27.

9. Chaiklin, Sh., "Hemos danzado desde que pusimos nuestros pies en la tierra", La vida es danza..., p. 28.

10. Thomas Shack es profesor y director del Grupo de Investigación en Neurocognición y Acción en la Universidad de Bielefeld. Es investigador principal en el Centro de Tecnología de 
Mientras baila, el actor normalmente no se para en elementos o detaIles, sino que experimenta la plenitud del ser en el aquí y el ahora y por lo tanto alcanza un nivel superior de comprensión e interpretación . (...) La fusión de la danza con el ambiente y las circunstancias se produce si no se planifican los movimientos o se piensan en los miembros y en sus movimientos cinemáticos. Esto puede suceder si los bailarines confían en su coordinación y capacidad para moverse libremente, con flexibilidad en el espacio y en el tiempo. El deseo de experimentar este estado una y otra vez podría haber sido una razón y motivación para bailar en general ${ }^{11}$.

"Trance" y "poder mágico inmanente" son expresiones utilizadas por Chaiklin para la danza de las culturas tribales primitivas y que es probable que apunten a esa sensación de desahogo, a esa supuesta "pérdida de consciencia del yo" a la que se refería Sachs. Thomas Shack, por su parte, hablando del baile en nuestros días alude a un sentimiento de "plenitud de ser en el aquí y el ahora" que es experimentado por parte del que baila en un escenario, hecho que conlleva un más alto nivel de conocimiento y de interpretación, continua diciendo. Junto a éste, existen multitud de testimonios a lo largo de la historia en este mismo sentido, notable por ejemplo es el de Isadora Duncan (1877-1927). Actualmente podríamos encontrar sin problema un sinfín de manifestaciones en esta misma línea tanto en la literatura relacionada como en cualquier medio de comunicación. ¿Es esa sensación de plenitud, esa supuesta pérdida de consciencia del yo que se da en ese estado "de éxtasis" una meta, un objetivo en la danza como parece sugerir Shack, o es más bien un medio, una manera de proceder -en mayor o menor grado dependiendo del tipo de danza y de las circunstancias- de toda aquella persona que danza?

\section{Perspectiva filosófica}

Desde la antigüedad ha existido un amplio consenso acerca de esta idea: la danza ha sido y es un arte. Así la hemos considerado nosotros en este trabajo. En el mundo griego de la época arcaica y clásica la cultura se transmitía generación tras generación de una manera fundamentalmente oral y era la obra literaria oral la que ayudaba a dar cohesión a una comunidad. Esta literatura oral unía tres artes que eran la música, la palabra cantada o poesía y la danza; los griegos lo denominaron con una sola palabra: mousiké o arte relacionado con las musas ${ }^{12}$. La mousiké fue considerada en el mundo griego como la más completa de las

Excelencia en la Interacción Cognitiva (CITEC) y miembro del Instituto de Investigación de Cog nición y Robótica (CoR Lab).

11. Shack, T., "Building blocks and architecture of dance", The Neurocognition of Dance. Mind, Movements and Motors Skills. Nueva York, Psychology Press, 2010, p. 11.

12. Gentili, B., Poesía y público en la Grecia antigua. Barcelona, Quaderns Crema, 1996, p. 59. 
artes para la educación del ser humano ${ }^{13}$. Artemis Markessinis en su obra Historia de la danza desde sus orígenes (1995) Ilega a decir que "la danza es la primera de las artes"14. También ha habido momentos en la historia en los que se ha matizado esta consideración. Fundados en 1932 en París, los Archivos internacionales de la danza (AID) en sus orígenes y rompiendo con una visión bastante arraigada contemplaron la danza desde una perspectiva más amplia, una perspectiva social e histórico-artística y no meramente como un fenómeno estético o una forma de arte ${ }^{15}$. En definitiva, a lo largo de la historia en mayor o menor medida, la danza ha sido considerada como un arte. No es objeto de este trabajo el detenernos en distinguir los innumerables tipos distintos de danza que han existido a lo largo de la historia ni el entrar en la dilatada tarea de definir qué es el arte. Nos vamos a referir aquí siempre a la danza o al baile genéricos, a la danza como expresión artística inherente al ser humano desde la antigüedad hasta nuestros días ${ }^{16}$. Y en cuanto al concepto de arte, nos acogemos a uno de los sentidos o acepciones de este concepto que más nos interesan, que nos parece esencial y que desde la antigüedad, como hemos visto, ha desempeñado un papel principal: consideramos que el arte es, ante todo, comunicación.

Cualquier manifestación artística del hombre es de alguna manera comunicación y a su vez, la comunicación humana participa de cierto grado artístico. Todo arte, cualquier obra artística sea de la naturaleza que sea trata de decirnos algo, de comunicar, de establecer una conexión entre el artista y el exterior, el resto del mundo. Hablando de danza dice Hilda Wengrower ${ }^{17}$ en La vida es danza (2008): "de hecho, la obra [artística] puede ser una pieza de expresión mucho más efectiva que una conversación o acción en la vida cotidiana"18. En el caso del arte de

13. Morenilla, C., "La danza y su presencia en el programa escolar en la Grecia clásica", II Jornadas de Danza e Investigación. (....). Barcelona, Los Libros de Danza, 2000, pp. 90100.

14. Markessinis, A., Historia de la danza desde sus orígenes, p. 15.

15. Archives Internationales de la Danse de París. Su trabajo Ilega hasta nuestros días, actualmente se pueden consultar en línea en la dirección www.cnd.fr

16. En este sentido Hortensia Völckers quien pertenece a la Fundación Federal Cultural de Alemania y entre 1991 y 1995 fue directora artística del Festival de Munich Dance, dice para fraseando a D. Diderot en la Gran Enciclopedia del Periodo de la Ilustración: "La danza y el can to son tan naturales para la humanidad como los gestos y la voz. Desde que ha habido seres humanos en la Tierra, sin duda ha habido canto y danza, la gente ha cantado y bailado desde el comienzo de la creación hasta nuestros días y es más que probable que la gente siga cantan do y bailando hasta que la raza humana se extinga completamente". Völckers, H., "Preface", Knowledge in Motion: Perspectives of Artistic and Scientific Research in Dance. Bielefeld, trans cript Verlag (German Federal Cultural Foundation), 2007, p. 13.

17. Hilda Wengrower es terapeuta DMT (Danza Movimiento Terapia) y docente en el Depar tamento de Estudios de Teatro de la Universidad de Jerusalén. Ha publicado artículos y capítulos relacionados con la DMT, la inmigración y la investigación cualitativa empleando las artes.

18. Wengrower, H., "El proceso creativo y la actividad artística por medio de la danza y el movimiento", La vida es danza..., p. 46. 
la danza la mayoría de los artistas estarán de acuerdo si se les pregunta, en que al bailar se expresa, se comunica algo. O sin ir más lejos, cualquiera de nosotros podemos responder a dicha pregunta en base a la propia experiencia que cada uno tenga con el baile. Isadora Duncan, una de las precursoras de la danza moderna, reivindicativa y revolucionaria en cuanto a la manera de entender la danza en su época, lo tenía muy claro en 1909: "No estoy interesada en bailar simplemente por bailar. Para mí la danza debe ser expresión de la vida no meramente una serie de trucos gimnásticos o movimientos bonitos" ${ }^{\prime 19}$. Y en otro escrito de 1915: "Y es que el cuerpo en sí mismo debe ser olvidado, porque no es más que un instrumento armonioso y bien adaptado cuyos movimientos expresan no sólo los movimientos del cuerpo, como en la gimnasia, sino también los pensamientos y sentimientos del alma" ${ }^{\prime 20}$. En el mismo sentido afirma Chaiklin (2008):

La danza no se limita a un ejercicio, sino que ante todo es una manifestación de los sentimientos y energías personales y un deseo de exteriorizar algo propio. La danza como creación, se basa en un concepto (...) que se necesita comunicar a los demás ${ }^{21}$.

Del mismo modo, consideramos que a su vez la comunicación humana participa en mayor o menor medida de cierto grado artístico, como decíamos. ¿Por qué? porque consideramos que comunicar es el arte de desplegar y compartir en un tiempo determinado algo interior, algo propio, algo de lo que en definitiva se es. Si nos situamos en la tradición existencialista-hermenéutica ese "algo de lo que se es" es algo que se ha comprendido y asumido en uno mismo, por lo tanto comunicar es desde este enfoque re-presentar, desplegar en un tiempo determinado lo adquirido, lo comprendido, lo asumido en un presente anterior ${ }^{22}$. De nuevo en el ámbito de la danza y acorde con lo que acabamos de señalar, Isadora Duncan en 1905 hace la siguiente afirmación: "Es el estudio de las figuras vivas que danzan espontáneamente cada una expresión de un alma individual, de su más profunda comprensión y de su poder personal (... $)^{\prime 23}$. Duncan concibe la danza espontánea (para ella, en rea-

19. Duncan, I., "Terpsícore", Isadora Duncan. El arte de la danza y otros escritos. Madrid, Akal, 2008, p. 94. Original del año 1909.

20. Duncan, I., "El teatro griego", Isadora Duncan. El arte de la danza..., p. 117. Original del año 1915.

21. Chaiklin, Sh., "Hemos danzado desde que pusimos nuestros pies en la tierra", La vida es danza..., p. 30.

22. En un "presente pasado" según la terminología empleada por Reinhart Koselleck (1923 2006) en: Koselleck, R., Futuro Pasado. Para una semántica de los tiempos históricos. Barcelona, Paidós, 1993.

23. Duncan, I., "Cómo debería ser la danza", Isadora Duncan. El arte de la danza..., p. 75. Original de 19051906. 
lidad, la única forma de danza auténtica) como expresión y por lo tanto comunicación de la más profunda comprensión del artista que baila.

Los hombres tenemos innumerables formas distintas de comunicarnos, de expresarnos y cada una de esas formas de expresión parece tener su velocidad de comunicación adecuada, su cadencia, su ritmo apropiado de expresión a través del tiempo: desde una mirada a los ojos de otra persona que puede expresar mucho en un corto espacio de tiempo hasta la lectura y/o escritura de un libro cuyo mensaje requiere bastante más tiempo de recepción y/o elaboración. Dentro de las múltiples formas de expresión artística que ha encontrado el ser humano a lo largo de la historia, situándonos en la tradición estética gadameriana y siendo conscientes de que ha sido necesaria una simplificación, nos hemos atrevido a establecer dos tipos de obras de arte tomando como uno de los principales criterios discernidores esa velocidad o ritmo de expresión. Por un lado diferenciamos aquellas obras de arte con una conformación estable, cuyo mensaje, cuyo significado está condensado, cristalizado en una forma estable que lo sostiene: una escultura, una pintura, una fotografía, una obra arquitectónica y también un libro, una poesía, incluso una partitura musical serían ejemplos de este primer apartado. Son obras de arte duraderas en las que significante y significado tienen una gran capacidad de sobrevivir a través del tiempo. Y por otro lado, distinguimos aquellas obras que hemos denominado obras de arte "in itinere" cuya conformación no es estable, es variable en el tiempo y cuyo significado se despliega igualmente en el tiempo a la vez que se va creando, desarrollando la obra: hablar, bailar, actuar en una obra de teatro o la interpretación de una partitura musical o de un texto serían ejemplos de este segundo apartado. Como vemos, las Ilamadas artes escénicas entrarían aquí. No hemos hecho una distinción entre creación e interpretación artística por considerar que la interpretación participa de la manera de ser de la creación, al menos en lo que al interés de nuestro enfoque se refiere: la comunicación inherente a la expresión artística del ser humano. La principal característica de estas últimas obras es su carácter agonal, son re-presentaciones cuya duración, cuya vida es corta, se crean y desaparecen en un corto espacio de tiempo. Estas obras sólo son durante el tiempo en el que son representadas; al igual que las anteriores, son en su re-presentación pero la diferencia es que sólo pueden ser una única vez, su naturaleza no estable no les permite durar en el tiempo, nacen y mueren en un corto periodo de tiempo, de ahí el que les hayamos atribuido ese carácter agonal. La danza pertenecería entonces a este segundo tipo de obras, se trata de una obra de arte "in itinere": su conformación no es estable y su significado, lo que sea que la danza quiera expresar o comunicar se despliega en el tiempo que dura la representación de la misma.

Hemos tomado el término "conformación" de la estética del filósofo HansGeorg Gadamer (1900-2002): para él una obra de arte condensa en una "conformación estable" un significado, un mensaje, una información, una comprensión previa de su autor. Si contemplamos la obra de arte como un sím- 
bolo formado por un significante y un significado, la conformación sería ese significante. Para este filósofo, que llega a desarrollar una auténtica ontología de la obra de $\operatorname{arte}^{24}$, lo que acontece en una obra es una dialéctica, una lucha entre la conformación estable (en mayor o menor grado, como hemos visto) y el significado o el mensaje que encierra esa obra de arte. Forma y significado, la obra de arte es la unión de ambos, el ímpetu de integración de ambos y no sólo lo uno o lo otro por separado. Habla Gadamer de la "identidad hermenéutica" de la obra de arte; desde este enfoque la obra constituye, ciertamente, un símbolo formado por un significante y un significado susceptible de ser interpretado y lo que simboliza la obra es aquello que el autor de la obra ha comprendido, aquello por lo tanto que el autor de la obra es. Es la obra de arte bajo esta perspectiva, una metáfora de su autor, de lo que comprende, de lo que él es, se trata como hemos señalado de una re-presentación: una réplica de ese momento presente anterior en el que el autor ha comprendido algo que quiere expresar. El artista creador, para crear su obra, obviamente ha desplegado esa comprensión en el tiempo mediante una técnica que materializa lo comprendido y además, creemos que mediante una disposición, una actitud, que hace el papel de guardián durante todo el proceso de creación de la fidelidad de la obra de arte a su fuente de comprensión. Esto último parece quedar claro cuando hablamos de obras de arte que tienen una conformación estable, las del primer tipo: una pintura, una escultura, un libro, etc. en las que se ha de materializar una idea, una comprensión previa mediante la técnica literaria, la técnica escultórica, la técnica pictórica, la técnica arquitectónica, etc. Pero ¿qué ocurre con el segundo tipo de obras, las que no tienen esa conformación estable?, ¿de qué manera se materializa una comprensión en el caso del arte de la danza, por ejemplo?, ¿se muestra válida en estos casos la perspectiva gadameriana de la "identidad hermenéutica" de la obra de arte? Queremos centrarnos en este asunto que a nuestro parecer es esencial porque no solamente abarca un determinado tipo de manifestaciones artísticas "in itinere" sino que afecta a un amplio espectro dentro de la comunicación humana. ¿Qué y de qué manera comprende el ser humano que despliega su obra artística durante una danza, una obra teatral, la interpretación de una partitura musical o la interpretación de un texto? y en definitiva, ¿qué y de qué manera comprende el ser humano en el proceso "in itinere" (continuo y dinámico) de diálogo con otro ser humano?

El arte de desplegar en un tiempo determinado y con una técnica concreta una idea, algo propio, una comprensión previa, creemos que no es tarea obvia ni fácil. Es más, creemos que ha de estar presidida y dirigida por una

24. Ma Antonia González Valerio hace un estudio de este tema en: González, M. A., El arte develado. Consideraciones estéticas sobre la hermenéutica de Gadamer. México, Herder, 2005. 
actitud concreta: la actitud del artista creador de la obra de arte. Decíamos antes que esta actitud, esta disposición del artista creador ha de desempeñar durante todo el proceso de creación el papel de guardián de la fidelidad de la obra de arte a su fuente de comprensión, como comúnmente decimos "a su fuente de inspiración". Una actitud es una predisposición y consideramos que participa, al igual que el hombre y que la comprensión, de la forma de ser de la historicidad: hunde sus raíces en el pasado, pero está orientada hacia el futuro. Es un estado anímico, tiene un componente emocional, pero sobre todo, el rasgo distintivo de la actitud es su marcado carácter práctico, orientado a la acción, a desarrollar una conducta determinada. El que la actitud participe del modo de ser de la historicidad implica que es algo variable, dinámico, siempre en construcción: su esencia pertenece a una fórmula variable en función del tiempo, en concreto, una fórmula cuya variable es la constante y dinámica imbricación en el tiempo entre la experiencia (pasada) y la expectativa (futura). En cualquier caso, desde la perspectiva hermenéutica, por ser la comprensión histórica y nunca acabada, siempre en construcción, la actitud del artista creador es aquella que le lleva a seguir comprendiendo durante ese proceso creativo. En definitiva, como se ha venido diciendo desde antiguo, aquella actitud que mantiene al artista inspirado ${ }^{25}$. Pero en esencia ¿es la misma actitud la que necesita un escritor al escribir un libro, un pintor al pintar un cuadro, un arquitecto al diseñar una casa, un actor al representar una obra teatral o un danzarín al bailar en un escenario? Parece lógico pensar que en función de los distintos ritmos o velocidades de expresión inherentes a las distintas disciplinas artísticas la actitud del artista creador tendrá unos matices u otros. Para empezar, esa actitud inspiradora se mantendrá dilatada en el tiempo en mayor o menor medida dependiendo de la disciplina. Otra diferencia de matiz importante que deducimos es que esa actitud inspiradora puede o no ser mantenida sin interrupciones durante el tiempo que dura la creación o re-presentación de la obra. A nuestro parecer el signo, una de las principales diferencias cualitativas de las obras de arte "in itinere" es ésta, que la actitud no puede o no debe ser interrumpida durante el tiempo que dura la representación de la obra ya que iría en detrimento de la calidad y de la autenticidad final de la misma (hecho que sí puede darse en el caso de las obras de

25. Sobre la inspiración, en concreto en el campo de la música nos parece interesante el trabajo del compositor Johathan Harvey (1939 2012) que desde los años ochenta creó nume rosas composiciones en el marco del IRCAM (trad.: Instituto de Investigación y Coordinación de Acústica Música). Considera que la experiencia de la inspiración musical engloba varias acepciones: "es física, comparable al acto de prepararse para cantar o interpretar; es espiritual, como los momentos de revelación religiosa; es inesperada, impredecible, y no puede confun dirse con ningún otro fenómeno." En: Harvey, J., Música e inspiración. Barcelona, Global Rhythm Press, 2008, p. 17. (El subrayado es nuestro). 
arte con una conformación estable: el artista creador puede interrumpir en el tiempo esa actitud inspiradora sin que suponga un detrimento de la calidad o autenticidad final de la obra). Con todo, estamos hablando en ambos casos de formas de expresión del hombre, con lo cual, en definitiva, la pregunta que nos hacemos en último término es: ¿cuál es la actitud correcta del ser humano que mantiene un diálogo auténtico con otro ser humano?

No podemos dejar de tener en cuenta el dato aportado por la psicología de que toda actitud tiene un componente emocional y por lo tanto neurofisiológico. Esto, ineludiblemente nos Ileva a preguntamos también ¿cuál es el papel concreto que juega el físico, el cuerpo del ser humano en la actitud?, pero, sobre todo, ¿qué papel juega el físico, el cuerpo del ser humano en la actitud del artista creador y por lo tanto en la comprensión? Este planteamiento tiene implicaciones muy complejas. Y entre ellas, el análisis de las artes "in itinere" como medio para arrojar alguna luz sobre él, en concreto, el análisis de aquel arte en el que el cuerpo humano juega un papel principal, aquel arte que utiliza el cuerpo humano como instrumento y como medio técnico para desarrollarse: la danza. Corinne Jola, del Departamento de Psicología de la Universidad de Glasgow parece tener claro que

Claramente, la forma en que el cuerpo funciona y la forma de la que está organizado, tiene un efecto en cómo percibimos e interactuamos con el mundo que nos rodea (...). El cuerpo es también un instrumento de expresión afectiva, de señales sociales y espaciales, tanto a través de la interacción verbal como de la no verbal (...). Por lo tanto, con estos aspectos en mente, está claro por qué la neurociencia cognitiva está interesada en la danza, y se espera que la investigación en danza pueda avanzar más de la mano de la investigación en neurociencia cognitiva. Soy positiva en cuanto a esta fructífera combinación ${ }^{26}$.

No perdemos de vista la perspectiva filosófica. En el marco de su propuesta de Filosofía del Límite, Eugenio Trías (1941-2013) afirma que comprender es en suma, hacer consciente lo inconsciente. En su obra La edad del espíritu dirá: "Se postula un reintegro de esa inconsciencia en la luz autoconsciente como la realización misma del espíritu" ${ }^{27}$. En Trías y en concreto a partir de la resolución final de esta obra, el espíritu se concibe como la unión existencial entre razón y simbolismo. Jose $M^{a}$ Aguirre habla en este sentido de una "razón amplia" que creemos, está en sintonía, recoge los matices que implica esa

26. Jola, C., "Research and choreography: Merging dance and cognitive neuroscience", The Neurocognition of Dance..., p. 209.

27. Trías, E., La edad del espíritu. Barcelona, Destino, 1994, p. 623.

28. Aguirre, J. Ma ., Ética y emancipación. Exploraciones filosóficas. Barcelona, Anthropos, 2015 , p. 387. 
unión ${ }^{28}$. En línea también con esa simbiosis, hay autores que defienden el peso esencial de la "imaginación creadora" en todas las disciplinas de conocimiento del ser humano, tanto artísticas como científicas, al proponer (con Wolfgang Welsch) que en la posmodernidad asistimos a un creciente proceso de "estetización epistemológica"29. Este enfoque sobre la comprensión es compartido también en otros ámbitos y otras disciplinas y nos parece de gran relevancia en este trabajo. Valgan como ejemplo estas palabras de Vicente Merlo al hablar de la psicología transpersonal como "psicología filosófica" o "antropología filosófica":

La teoría transpersonal no supone una recaída en la oscura irracionalidad, en un mundo de supersticiones medievales ya superado, sino que pone en cuestión la afirmación de que la inteligencia racional, instrumental, calculadora, constituya la única manera de entender y de operar la inteligencia y afirma que existe una inteligencia intuitiva, anímica, espiritual, transpersonal, capaz de "percibir y comprender" de otro modo $(\ldots)^{30}$.

En la concepción transpersonal, esa "inteligencia transpersonal" se da desde un ámbito que mantiene en contacto el consciente personal, el supraconsciente personal y el inconsciente colectivo.

Habíamos hablado de que la obra de arte contiene una comprensión previa de su autor, y en este sentido, es también relevante para este trabajo la aportación de Trías de que el instante de la creación genial del artista es a la vez consciente e inconsciente. Dirá: "En el instante-eternidad de la creación genial, a la vez consciente e inconsciente, los dualismos (...) quedan superados en un acto de creación que es, también conocimiento clarividente (o intuición intelectual, como dirá Schelling)"31. Esta perspectiva es defendida también por otros pensadores no sólo en el ámbito de la filosofía o la psicología; ya hemos mencionado en el ámbito musical, el ejemplo del compositor Jonathan Harvey. Algo similar nos da a entender Sachs en el ámbito de la danza en la antigüedad, al atribuir el gran desarrollo que se produce en un momento dado en la danza enmascarada, a la fructífera combinación entre dos "fuerzas básicas" como él las Ilama, la imaginativa y la sensorial:

Ya hemos visto en la danza enmascarada la potente y fructífera unión de las dos fuerzas básicas: la abstracta, introvertida, sin imágenes y la sensorial, extrovertida, de poder imitativo. El gran desarrollo que se verifica

29. Bermejo, D. (ed.), "Estetización epistemológica", En las fronteras de la ciencia. Barcelona Logroño, Anthropos Universidad de La Rioja, p. 81.

30. Merlo, V., Filosofía, ¿qué es eso? Saber y ser en Occidente y Oriente. Madrid, Biblioteca Nueva, 2014, p. 113.

31. Trías, E., La edad del espíritu, p. 624. 
ahora recibe su potencial de la misma combinación de la facultad imaginativa dedicada al culto de los antepasados con la sensorial en la objetivación de la danza imitativa ${ }^{32}$.

A raíz de lo anterior, podríamos pensar, aunque no sea mas que metafóricamente, que existe algo así como un ámbito intersticial entre consciente e inconsciente (teniendo muy en cuenta que éstos pueden ser individuales y/o colectivos) y que es éste un ámbito prolífero artísticamente. Participaría este hipotético ámbito de algunas de las características de lo que Trías ha denominado en su propuesta filosófica el límite. En cualquier caso, lo que parecen poner encima de la mesa todos estos autores, ya sin metáforas, es que la actitud del artista creador ha de ser aquella que consiga mantener en contacto de algún modo consciencia e inconsciencia, aquella que abra de alguna manera una vía de unión entre consciente e inconsciente. Ahora bien, ¿puede el ser humano llevar a cabo esto de manera intencional a través de su voluntad?, ¿es esto algo que sucede de manera espontánea, sin previo aviso y sin intervención de la voluntad humana?

Centrándonos en el arte de la danza y en concreto, en qué es lo que le ocurre a la persona que baila, de nuevo hemos de mencionar en este punto a Sachs quien afirma: "es evidente la derrota de las limitaciones que presupone la condición corporal del hombre, liberándose el subconsciente al danzar"33. Esta afirmación, un tanto ambigua, parece poner en juego en aquella persona que danza los dos aspectos relevantes que mencionábamos, consciencia e inconsciencia y nos interesa incidir, sobre todo, en ese juego o dialéctica que parece llevarse a cabo en la danza entre los dos. Si esto es así, si el artista durante el baile deja abierta ¿voluntariamente? esa vía que enlaza lo consciente con lo inconsciente y permanece en contacto con los dos, significa por un lado, que durante su re-presentación se mantiene cognitivamente en contacto con su cuerpo y por supuesto con el entorno (con la música, principalmente) y es capaz de jugar con estos factores de manera fluida, tendiendo constantemente a que ese juego suceda de manera no intencional ${ }^{34} \mathrm{y}$ por otro, significa que al mismo tiempo, es capaz de controlar tanto las percepciones

32. Sachs, C., Historia Universal de la Danza, p. 240.

33. Sachs, C., Historia Universal de la Danza, p. 37.

34. En este punto, de acuerdo con la manera de entender Gadamer la obra de arte: para él, el juego es el modo de ser de la obra de arte. En Gadamer, H. G., Verdad y método: Fundamentos de una hermenéutica filosófica, Salamanca, Sígueme, 1988, p. 143. Define Gadamer el jue go como "la pura realización del movimiento, repetición, vaivén constante... tratándose además de un movimiento realizado sin objetivo, sin intención y por lo tanto sin esfuerzo. (...) Cuando el juego humano se transforma en arte alcanza su perfección y su identidad puesto que se muestra independiente de los jugadores y aparece como una conformación, como algo per manente (...)." En González, M. A., El arte develado..., p. 51. 
conscientes de -y a través de- su cuerpo, como las habilidades sensoro-motoras inconscientes que han sido incorporadas, automatizadas previamente a través del ensayo. Por supuesto, en este punto es fundamental para el artista el papel de la música, aspecto en el que no nos vamos a detener demasiado aquí, simplemente queremos señalar que tal y como afirma Trías la música "crea un ambiente" un ambiente apropiado para ser habitado temporalmente ${ }^{35}$. Dice Trías:

Lo ambiental, el ambiente, lo constituye el nexo entre el territorio y el cuerpo (...). La arquitectura y la música son artes ambientales que dan forma y determinan el carácter y la cualidad de la atmósfera o del aire que se produce entre el cuerpo y el ambiente. (...) en la música y en la arquitectura se da salida y vehículo a esas producciones inconscientes que se instalan en el preconsciente ${ }^{36}$.

Vemos que esta consideración que Trías hace sobre la música incide en el diálogo consciencia-inconsciencia que señalábamos. También el compositor musical Jonathan Harvey afirma: "El inconsciente es relevante (...) ya que es la acción del estímulo exterior sobre el inconsciente lo que ofrece las posibilidades más fértiles para la inspiración musical"137. Dejando a un lado el aspecto musical en la danza, ¿es correcto el razonamiento que nos habíamos planteado?, ¿podemos afirmar que en el baile se mantiene abierta esa conexión consciente-inconsciente? Y si es así, ¿es éste un hecho que se produce de manera intencional, voluntaria? Recordemos que, como hemos mencionado, para Harvey una de las acepciones que engloba la inspiración es que es inesperada, impredecible. Encontramos testimonios de profesionales de la danza e investigadores en esta disciplina en la actualidad que pueden arrojar alguna luz con su experiencia sobre estas cuestiones.

Inge Baxmann, en su artículo "The body as an archive" (2007) habla de la obra The techniques of the body (1934) de Marcel Mauss. En ella afirma Mauss que "cada técnica del cuerpo tiene su propia forma específica, se transmite, se adquiere, vincula consciente e inconsciente y codifica las percepciones corpo-

35. Trías, E., "Estética del límite", Creaciones Filosóficas I. Ética y estética. Barcelona, Gala xia Gutenberg Círculo de Lectores, 2009, p. 222. Se trata de un escrito perteneciente origina riamente a su obra anterior Lógica del límite, 1991. Dice Trías: "la música nos envuelve, como en general toda sonoridad ambiente, del mismo modo en que nos envuelve el ámbito que deter mina la arquitectura. Crea una segunda naturaleza ya formada en relación con la primera, salvaje y sin cultivar. Ambas, arquitectura y música, se sitúan en el quicio mismo entre natura leza y cultura, o entre materia y forma, o entre lo prelingüístico y el logos elaborando y dando forma a ese intersticio fronterizo".

36. Trías, E., "Estética del límite", Creaciones Filosóficas I..., p. 228.

37. Harvey, J., Música e inspiración, p. 28. 
rales y la experiencia social" ${ }^{\prime 38}$. Wengrower y Chaiklin en la introducción de La vida es danza (2008) hablan de la DMT (Danza Movimiento Terapia): "La danza y el movimiento son empleados como vías de acceso al inconsciente $(. . .)^{\prime \prime 39}$. Diana Fischman en la misma obra (2008) afirma hablando también de la DMT:

A nivel individual, el movimiento incluye tonalidades afectivas que se expresan inevitablemente aunque en ocasiones permanecen inconscientes para el propio actor. Un sistema complejo de procesos y grados de tensiónrelajación muscular posibilita la manifestación de las mismas. (...) La eficacia de la DMT se relaciona con su posibilidad de trabajar con la conciencia de las experiencias corporales donde estas emergen o donde se recrean y repiten. Así es como la DMT opera en el lugar donde confluyen sensación y sentido ${ }^{40}$.

Un poco más adelante habla de la propuesta de la DMT como dispositivo teórico-clínico que complementa la labor del psicoanálisis relacional puesto que permite operar allí donde las palabras no son suficiente vía de contacto y encuentro. Por consiguiente, la DMT redunda en los planteamientos de este tipo de psicoanálisis el cual defiende que "además de la narración y la recuperación de recuerdos para hacer consciente lo inconsciente también deben atenderse las vivencias afectivo-perceptivas y espacio-temporales".

Merece la pena en este momento considerar brevemente desde la perspectiva actual de la ciencia cognitiva, aquellas aportaciones que puedan arrojar alguna luz o matizar las ideas hasta aquí expuestas. Harvey (2008) dice en el "Epílogo" de su obra:

Maneras de pensar que hoy consideramos ortodoxas a menudo fueron elaboradas contra unas rutinas demasiado complacientes por parte de colegas menos perceptivos. La necesidad de desafiar las opiniones aceptadas no es menos vital en nuestra época. (...) Además, la forma en que nos acercamos a nosotros mismos también está cambiando. Poco tiempo atrás prevalecían postulados mecanicistas según los cuales teníamos el control completo de una mente separada de la materia, la cual obedecía mecánicamente a sus propias leyes. Ahora estos planteamientos nos parecen demasiados rígidos, demasiado simples $(. . .)^{41}$.

38. Baxmann, I., "The body as an archive", Knowledge in Motion..., p. 208. Inge Baxmann es profesora de estudios de Teatro, estudios de Danza e Historia de la Danza en la Universidad de Leipzig.

39. Wengrower, H. y Chaiklin, Sh. (coords.), La vida es danza..., p. 22.

40. Fischman, D., "Relación terapéutica y empatía kinestésica", La vida es danza..., pp. 8385. Diana Fischman (Argentina) es terapeuta DMT (Danza Movimiento Terapia), profesora en Ciencias de la Educación y licenciada en Psicología. Investiga principalmente sobre empatía kinestésica.

41. Harvey, J., Música e inspiración, p. 215. 


\section{Aportaciones de la ciencia cognitiva}

En el marco de las recientes investigaciones en el campo de la ciencia cognitiva sobre la naturaleza del pensamiento humano son numerosos los autores que defienden una postura anti-cartesiana y anti-aislacionista. Es decir, la cognición no se entiende, en estos autores, como un proceso mental separado y aislado del cuerpo donde el cerebro es el centro ejecutivo que Ileva a cabo un razonamiento de alto nivel (idea común desde que Descartes, en el siglo XVII, sentase las bases del dualismo cartesiano como base y principio de la cognición humana). Esta nueva perspectiva aboga por abandonar la línea divisoria entre percepción, cognición y acción ${ }^{42}$ (factores todos ellos sobre los que interviene voluntariamente la atención humana). Antecedentes de este enfoque los podemos encontrar en la obra del filósofo francés Maurice Merleau-Ponty (19081961 ) entre otros, quien propone, en este sentido, el concepto de cuerpo-sujeto mediante el que trata de superar la concepción dualista de que el cuerpo es lo opuesto al espíritu, mente o alma. Huye de un materialismo que subordine lo incorpóreo al cuerpo y huye a la vez de un idealismo que subordine el cuerpo a la parte incorpórea. Insiste en que el ser humano es una realidad material y espiritual al mismo tiempo y defiende una "vital e intensa relación dialéctica" tanto a nivel consciente como a nivel preconsciente, entre esas dos realidades: la material y la llamada por él "espiritual"43. Recientemente en la obra del filósofo español Eugenio Trías encontramos este mismo enfoque sobre cognición que él define como "pluralidad epistemológica": afirma que el "ser que soy" queda trascendido en el "ser que somos" y que en consecuencia "conocer no significa ya el encuentro del objeto físico con el sujeto ante el cual éste comparece sino el encuentro entre diversos sucesos físicos que son sujetos virtuales de conocimiento $^{\prime \prime 4}$. Apuesta este autor por una desintegración del tradicional núcleo epistemológico par sujeto-objeto defendiendo una pluralidad interconexa de sucesos físicos relativos e interactuantes ${ }^{45}$.

Como vemos estos autores y otros relevantes en este campo (Van Gelder, Gallagher, Clark, Nöe, Varela, etc.) abogan por una integración o interactuación entre la mente, el cuerpo y el entorno del ser humano a la hora de conocer cualquier circunstancia. Como hemos señalado, rechazan cualquier distinción cognitivamente importante entre los procesos internos y los externos ${ }^{46}$ (entre

42. Clark, A., Being there. Putting brain, body and world together again. Cambridge (Mas sachusetts), The MIT Press, 1996, pp. xii xiii.

43. Aguirre, J. Ma ., ¿Conoces a estos filósofos? Estudios de filosofía contemporánea. Madrid, Síntesis, 2015, pp. 191 y ss.

44. Trías, E., Los límites del mundo. Barcelona, Destino, 2000, pp. 210215.

45. Trías, E., Los límites del mundo, pp. 204206.

46. Así por ejemplo en Clark, A., "Incorporización y la Filosofía de la Mente", Contrastes Revista Internacional de Filosofía. Supl. VI 2001, Málaga, 2001, p. 26. 
percepción, cognición y acción). En las últimas décadas, por lo tanto, se ha producido una importante evolución en las teorías cognitivas partiendo de una postura tradicional desde Descartes, aislacionista y estática hacia otra que considera la cognición y el pensamiento humanos como anticartesianos, integrados o incorporados y dinámicos. Estamos hablando entonces, en estos autores, de que el ser humano conoce a través de una interacción -temporal y espacialmente extendida- entre cuerpo, mente y entorno.

Por otra parte, el filósofo Shaun Gallagher ${ }^{47}$ (2005) hace referencia a la dialéctica consciente-inconsciente a nivel cognitivo, al proponer la distinción entre la imagen corporal de una persona, como el sistema de percepciones, actitudes y creencias en cuanto al propio cuerpo (por lo tanto un aspecto mayormente consciente) y el esquema corporal, como el sistema de capacidades sensoromotoras que funcionan sin consciencia ni la necesidad de vigilancia perceptual (aspecto mayormente inconsciente). Afirma Gallagher que en último término, el esquema corporal puede influir en la imagen corporal. De hecho, parece lógico pensar que existe una interrelación entre ellos: cualquiera de nosotros podemos confirmar la experiencia de que la repetición consciente de un determinado gesto en el que interviene la percepción del propio cuerpo (imagen corporal) puede llevar a integrar ese gesto en el esquema corporal definido por Gallagher a través del sistema sensoro-motor. Ese gesto, consciente en origen, pasa a formar parte de las habilidades o capacidades sensoro-motoras de la persona y después de un determinado tiempo de entrenamiento o de repetición pasa a realizarse de manera espontánea, inconsciente, sin necesidad de vigilancia perceptual. Hablamos de lo que comúnmente llamamos proceso de automatización de un movimiento y al que nos hemos referido brevemente al hablar de la práctica de la danza. A ésto se refería también Sachs al hablar de la danza primitiva que se ejecutaba imprimiendo golpes rítmicos a cada movimiento corporal: después de una serie de ejecuciones reiteradas llegaba un momento en el que los movimientos se ejecutaban de manera automática, sin intervención del sentido del yo.

En general, la mayoría de los defensores del anti-aislacionismo y anti-cartesianismo cognitivo argumentan en contra de la existencia de representaciones internas durante el proceso cognitivo puesto que ello implicaría la idea cartesiana de que el cerebro humano actúa de manera independiente del cuerpo al crear una imagen de éste. Sin embargo, estudios recientes ponen de manifiesto el hecho de que sí necesitamos cierta información, cierto tipo de "representaciones mentales pragmáticas" sobre el estado de nuestro propio cuerpo si queremos moverlo. A este respecto Andy Clark, aboga por un "cartesianismo mínimo" como él lo llama para describir la cognición humana ${ }^{48}$. Propone la existencia de

47. Gallagher, Sh., How the Body Shapes the Mind. Oxford, Oxford University Press, 2005.

48. Clark, A., "Incorporización y la Filosofía de la Mente", Contrastes..., pp. 30 y ss. 
un cartesianismo mínimo en el proceso cognitivo a la hora de emprender una acción concreta, explicando que es necesario para un acoplamiento satisfactorio en tiempo real entre orden motora y ejecución y que puede ayudar en el ensayo mental desacoplado ambientalmente de la acción como lo demuestran diversos estudios recientes. Al hablar de ensayo mental, consciente pero desacoplado ambientalmente, hablamos de la utilización consciente de imágenes mentales de una acción corporal concreta sin que ésta se llegue a realizar. Este tipo de ensayo mental tiene repercusiones en cuanto a la eficacia de la ejecución de esa acción corporal a posteriori, como ha quedado patente en varios estudios recientes, como el de Fetz y Landers (1983), en los que se ha demostrado que el rendimiento en una determinada práctica deportiva mejora cuando se combina anacrónicamente el entrenamiento tradicional con el ensayo a través de imágenes mentales de la habilidad deportiva específica que se pretende mejorar ${ }^{49}$. También ha quedado patente este hecho en el ámbito de la danza donde, igualmente, hay evidencias científicas en este sentido. Martin Puttke (2010) nos habla de la efectividad del "entrenamiento ideokinético" refiriéndose al método utilizado con sus alumnos de danza en el que combina este tipo de representaciones mentales de las posturas o pasos de baile con el entrenamiento convencional. Afirma Puttke, que este tipo de entrenamiento es especialmente útil en el trabajo con alumnos que tienen algún tipo de lesión y que tienen problemas para desarrollar el entrenamiento cinético convencional ${ }^{50}$.

Nos hacemos cargo de la novedad que supone este enfoque de la cognición integrada, de sus importantes implicaciones y de las imbricaciones que puede tener con la investigación en danza. Como afirma Bettina Bläsing (2010):

Para los bailarines, la idea de que pensar, comprender y aprender comienza con el cuerpo no es nada sorprendente. ¿Cómo debería ser de otra manera? Esta es, en mi opinión, una de las razones por las que el arte de la danza y la ciencia cognitiva pueden formar una alianza muy fructífera ${ }^{51}$.

49. Fetz, D. y Landers, D., "The Effects of Mental Practice on Motor Skill Learning and Per formance: A Meta Analysis", Journal of Sport Psychology. No 5, 1983, pp. 25 57. Véase también en esta misma línea el estudio de Gaggioli, A., Morganti, L., Mondoni, M. y Antonietti, A.: "Benefits of Combined Mental and Physical Training in Learning a Complex Motor Skill in Bas ketball", Psychology. No 4, 2013, pp. 16.

50. Puttke, M., "Learning to dance means learning to think!", The Neurocognition of Dance..., pp. 102 y ss. Martin Puttke ha sido director artístico de varias compañías de ballet en Ale mania (entre ellas la Escuela de Ballet del Estado de Berlín) y en la actualidad es un renombrado pedagogo del ballet. Ha desarrollado su propia metodología de enseñanza basada en los últi mos descubrimientos en el campo de la neurocognición y la biomecánica.

51. Bläsing, B., "The dancer's memory. Expertise and cognitive structures in dance", The Neurocognition of Dance..., p. 76. Bettina Bläsing es investigadora científica en el Grupo de Investigación en Neurocognición y Acción en la Universidad de Bielefeld. Es investigadora res 
En lo que concierne al objeto de este trabajo, nos parecen muy interesantes las distintas aplicaciones de los hallazgos de la ciencia cognitiva que se han llevado a cabo en la danza actualmente y sobre todo, la eficacia y repercusión de esas aplicaciones. Ejemplo de ello es el trabajo de Puttke a través de su insólito sistema de enseñanza en danza mediante los mencionados ensayos mentales desacoplados ambientalmente. Otro ejemplo de este tipo de aplicaciones lo encontramos en Bläsing (2010) al hablar del trabajo cognitivo, verbal, que es necesario realizar en el aprendizaje en danza cuando se intenta corregir un movimiento que ha sido previamente automatizado:

La estrecha interacción entre la memoria no-declarativa y la memoria declarativa se hace especialmente evidente cuando tratamos de aplicar correcciones a movimientos ya automatizados. El primer paso útil en el des-aprendizaje de un viejo error es a menudo encontrar una descripción verbal de lo que va mal y lo que debe hacerse en su lugar. El lenguaje puede proporcionar claridad a los pensamientos y puede usarse como una herramienta para manipular partes del conocimiento ${ }^{52}$.

Citamos una vez más al compositor musical Jonathan Harvey (2008) quien pone de manifiesto el deber que tiene el arte de estar a la altura de su tiempo e intentar dar una respuesta a "lo nuevo" que se presenta en cada época:

También nuestra época debe generar lo nuevo desde su interior. Somos cada vez más conscientes de que los seres humanos estamos inextricablemente unidos al resto de la naturaleza, y el deber de los artistas es dar una respuesta a ello ${ }^{53}$.

\section{De nuevo, la perspectiva filosófica}

¿Qué es lo que hace que una obra de arte sea auténtica? ¿Cuál es el criterio estético que hace que una obra de arte sea válida y otra no? Eugenio Trías se plantea esta misma cuestión a través de las siguientes palabras en Vértigo y pasión (1997):

¿Qué es lo que confiere a un objeto, a una obra o a cosas por el estilo el distintivo de obra de arte? (...) El arte y la estética permiten que esa cuestión brote con espontaneidad. Pero la respuesta a la misma aun cuando intuitivamente se imponga en cada caso concreto, se trueca en una de las

\footnotetext{
ponsable en el Centro de Tecnología de Excelencia en la Interacción Cognitiva (CITEC) y miem bro del Instituto de Investigación de Cognición y Robótica (CoR Lab).

52. Bläsing, B., "The dancer's memory. Expertise and cognitive structures in dance", The Neurocognition of Dance..., p. 83.

53. Harvey, J., Música e inspiración, p. 216.
} 
más difíciles soluciones que debe abordar la teoría del arte y la estética y en general la filosofía. Se trata del problema inherente al criterio estético ${ }^{54}$.

Propone Trías en su filosofía la existencia de una conflictividad originaria de carácter ontológico entre dos potencias a las que Ilama potencia conjuntiva y potencia disyuntiva, que por supuesto operan también en el ámbito de la estética. Considera que esa conflictividad, esa lucha, se encuentra en la esencia de toda realidad. Su propuesta de criterio estético discernidor de la obra artística es que "en toda verdadera obra de arte se da exposición sensible a esta lucha (...). Ha de mostrarse el combate por el predominio en la obra de estas dos grandes potencias" 155 . Notamos en su propuesta estética una clara proximidad con el pensamiento estético de Heidegger, quien recordemos, piensa que toda obra de arte lleva implícita una tensión a la que denomina "lucha entre mundo y tierra", así como con el pensamiento estético de Gadamer que habla del "juego de ocultación y mostración del ser" que tiene lugar en toda obra de arte y, como ya hemos mencionado, de la "identidad hermenéutica" de la misma (tensión entre la conformación y la apertura de significados). Para estos autores y también para Trías, la realidad y el arte comparten la misma esencia y ésta es expresada en términos de lucha, tensión, juego o dialéctica. La pregunta que debemos hacernos en este momento es, ¿cuál sería el criterio estético en el caso de la danza? No es una pregunta fácil de responder. Una posible respuesta es que la autenticidad en las obras de arte "in itinere" y en concreto en la danza, queda avalada por una actitud mantenida en el tiempo, por una disposición afectiva ${ }^{56}$ concreta del agente ejecutor de la danza. En este sentido, Puttke (2010) afirma:

Cualquier demostración ostensiblemente técnica o corrección visible destruiría la expresión artística. Esto coloca cargas emocionales, mentales y físicas de la más alta intensidad en la persona, cargas que por regla general se encuentran sólo en los límites dentro de los cuales funcionamos ${ }^{57}$.

De acuerdo con esta afirmación de Puttke y con lo ya analizado, esta disposición afectiva quizá tenga que ser una en concreto durante el baile: aquella que

54. Trías, E., "El criterio estético", Creaciones Filosóficas I. Ética y estética. Barcelona, Gala xia Gutenberg Círculo de Lectores, 2009, p. 347. Se trata de un escrito perteneciente origina riamente a su obra anterior Vértigo y pasión, 1997.

55. Trías, E., "El criterio estético", Creaciones Filosóficas I, p. 357.

56. El término está tomado de Martin Heidegger (1889 1976). Nos parece interesante en este punto recordar que en Heidegger, la disposición afectiva y la comprensión abren el estar en el mundo del ser humano (ser ahí, ser situado o dasein en la terminología heideggeriana) es decir, constituyen su apertura originaria al y en el mundo. En: Heidegger, M., Ser y tiempo. Madrid, Trotta, 2003.

57. Puttke, M., "Learning to dance means learning to think!", The Neurocognition of Dance..., p. 104. 
permita que el diálogo interno entre ese cuerpo, esa mente y esas emociones del artista (Puttke), tienda a fluir de tal manera que deje ser, transcurrir a la danza en todo momento. Sin olvidarnos también de ese propuesto como deseable diálogo o conexión entre el consciente y el inconsciente del artista. En relación a ese diálogo interno dice Puttke:

Se plantea una interrelación muy complicada entre la persona del artista (sujeto) y el cuerpo como instrumento de expresión artística (objeto). Esta relación muy particular de sujeto-objeto crea una interfaz particular entre la danza y la ciencia cognitiva que requeriría una colaboración interdisciplinaria de la psicología, la neurociencia, la biología y la filosofía, entre otras disciplinas, para ser entendido. (...) No hay ninguna otra profesión, o en todo caso ninguna que pueda pensar después de una larga consideración, que exija una interacción tan compleja entre el cuerpo y la mente a un nivel tan alto ${ }^{58}$.

Como hemos señalado con anterioridad, la actitud participa del modo de ser de la historicidad y estas palabras de Trías sobre la "verdadera obra de arte" deberían ayudarnos a vislumbrar algún matiz de esta actitud que intuimos y a la que nos referimos:

Toda verdadera obra de arte revela la unidad latente en los tres éxtasis temporales; echa lazos con el pasado, con la tradición en que se inscribe, que en ella es siempre convenientemente recreada. Pero está, asimismo, preñada de un futuro. Un futuro que la recepción terminará convalidando $(. . .)^{59}$.

Y es que quizá tengan que ver con la mencionada idea del "cuerpo como un archivo" de Baxmann (2007) refiriéndose a la concepción de Marcel Mauss de que cada técnica del cuerpo se adquiere, se transmite, vincula consciente e inconsciente y codifica las percepciones corporales y la experiencia social.

Norbert Servos (2007) en su artículo "What the body remembers" habla de cómo la artista Pina Bausch trabaja con sus bailarines para mantener su repertorio de danza actualizado ${ }^{60}$. En relación a la actitud de sus bailarines dice Pina Bausch: "Los pasos siempre vienen de algún otro sitio; nunca vienen [sólo] de las piernas" ${ }^{\prime \prime}$. Pina Bausch tiene claro que la autenticidad de sus creaciones

58. Puttke, M., "Learning to dance means learning to think!", The Neurocognition of Dance..., p. 104.

59. Trías, E., "El criterio estético", Creaciones Filosóficas I..., p. 361.

60. Servos, N., "What the body remembers", Knowledge in Motion..., p. 185. Norbert Ser vos (Alemania) ha trabajado como coreógrafo desde 1983. Cofundó y ha sido editor de la revis ta Ballet International y ha sido el director artístico del Dance Lab Berlin desde 1993. Es profesor de danza contemporánea y de coreografía.

61. Servos, N., "What the body remembers", Knowledge in Motion..., p. 187. 
pasa por un proceso interno en el bailarín en el que éste conecta con sus experiencias personales de tal manera que el movimiento no proceda sólo de las piernas. Explica Servos: "El objetivo no es hacer que esta particular historia interna sea visible para el público. Su objetivo es lograr una cierta calidad y precisión en la ejecución" ${ }^{62}$.

\section{Consideraciones finales}

A la luz de lo desarrollado hasta aquí podemos argumentar que en cualquier representación artística "in itinere" y en concreto en la danza, lo que se da es una comunicación o expresión de esa otra comunicación interna o diálogo interior del artista. Diríamos que existe durante la danza una dialéctica interna en la persona que baila que de algún modo pone en conexión y en juego, cuerpo, mente, consciencia e inconsciencia y que a su vez esa dialéctica dialoga con el entorno y en su caso con el espectador. Esto nos Ilevaría a considerar la danza, al igual que el juego que ha alcanzado su autonomía y que es observado por un espectador como metacomunicación. Analizar y desarrollar las implicaciones que tiene esta perspectiva creemos que abre una vía de investigación interesante, que implica no sólo al agente que danza sino también a aquel otro que observa danzar a alguien.

Eugenio Trías habla de la necesidad de habitar lo que él ha denominado límite, de transitar y hacer nuestro ese espacio intersticial o espacio lógico en el que, afirma, reside la verdad. Para él, es en ese espacio lógico (al que, afirma, se accede a través de la ética y se transita mediante la estética) donde se hace consciente lo inconsciente, donde se comprende. Recordemos, sin embargo, que en Trías el arte conduce a la verdad, no a la realidad y contrasta esa verdad con la realidad: el "viaje" que el arte promueve en la experiencia que de él hacemos "posee siempre billete de vuelta" a la realidad, dirá Trías ${ }^{63}$. Análogamente, en la danza, en el baile, pero también y sobre todo en la vida cotidiana creemos necesario habitar nuestro cuerpo. Esto significaría conocerlo, ser conscientes de él, tener una comunicación fluida con él, estar atentos a nuestro cuerpo, saber cómo reacciona y de qué manera se reflejan en él los hechos y las circunstancias. En este sentido afirma Fischman (2008):

Para la teoría de la enacción es inherente concebir el conocimiento como acción en el mundo y por tanto, como movimiento. (...) Igual tratamiento recibirán los términos enraizar (...) y encarnar (...) y sostendremos

62. Servos, N., "What the body remembers", Knowledge in Motion..., p. 188.

63. Trías, E., "Lo bello y lo siniestro", Creaciones filosóficas I., p. 146. El escrito original es de 1982. 
que ambos apuntan a la idea de habitar el cuerpo. (...) Hay varios autores que previenen de no dar por sentada la vida en el cuerpo $(. . .)^{64}$.

Habitar, comprender y conocer nuestro cuerpo creemos que significa avanzar en el camino del auto conocimiento, en línea con lo defendido por Sheets Johnstone en "On the hazards of being a stranger to oneself" (2008), con el fin de evitar o minimizar los peligros de ser "un extraño para nosotros mismos". Transitar ese camino de auto comprensión y por lo tanto, de comprensión del mundo, es lo que creemos que puede aportar de manera privilegiada la práctica de la danza (así como otras técnicas corporales, obviamente con matices distintos en cada una: mindfulness, pilates, yoga, etc.), despertando en nosotros "una racionalidad encarnada, conectada con nuestro sentir y nuestras emociones" 65 en el marco de una "racionalidad amplia" (Aguirre). La actitud necesaria para la práctica de esta disciplina y/o la actitud que se construye mediante la práctica de la misma, creemos que puede ayudar de alguna manera en el proceso de reconducción o reajuste de la actitud en nuestra vida diaria, hacia un enfoque más coherente, más libre y más justo (más ético) de los hechos cotidianos, quizá en línea con lo que Jose $M^{a}$ Aguirre ha denominado una "actitud emancipado$\mathrm{ra}^{\prime \prime 66}$. Seguramente, no en vano los griegos incluían la danza en la formación de los niños en sus escuelas, y la consideraban esencial en la formación del carácter de la persona ya que a través de ella se lograba la sofrosyne, la tan valorada por ellos virtud de la templanza:

La causa profunda de esa presencia de la danza en la formación es lo que los griegos entendían por ritmo: para ellos ritmo no era el modo de fluir o de moverse (...); ritmo es el esquema de las cosas, es decir, la disposición natural y ordenada que deben tener todas las cosas, incluidas las personas, encauzadas en unas pautas de comportamiento o movimiento. Por lo tanto, aprender un ritmo es imponer una limitación al movimiento en un determinado sentido, con lo cual se logra el conocimiento, por mímesis, de aquello que es ejecutado mediante la danza y a la vez se disciplina carácter y cuerpo. Se trata, por lo tanto, de conseguir el autodominio en todos los sentidos,

64. Fischman, D., "Relación terapéutica y empatía kinestésica", La vida es danza..., pp. 83 84. En concreto, Fischman menciona a Berman (1990, 1992), Caldwell (1999) y Winnicott (1979) como autores que "previenen de no dar por sentada la vida en el cuerpo".

65. Fischman, D., "Relación terapéutica y empatía kinestésica", La vida es danza..., p. 95.

66. Aguirre, J. Mª ., Ética y emancipación... La idea de emancipación es nuclear en el pen samiento de este filósofo. La obra mencionada refleja con profundidad su perspectiva filosófica defensora de una razón hermenéutica crítica emancipadora. Puede verse también en otros escri tos del mismo autor como en: Aguirre, J. M ${ }^{\mathrm{a}}$., "Ética, mundialización y emancipación", Retos y perspectivas de la filosofía para el siglo XXI. Barcelona Logroño, Anthropos Universidad de La Rioja, 2014, pp. 199219. 
de lograr la sofrosyne (templanza, moderación...), la virtud más importante para los griegos de la época clásica, y junto con ella, la belleza física ${ }^{67}$.

A raíz de todo lo expuesto, no parece desorbitado afirmar que el hombre haya encontrado desde antiguo en la danza una de las maneras de avanzar hacia el conocimiento y hacia la comprensión de sí mismo y de su entorno, así como de entrar en comunión con otros hombres. Concluimos este estudio, apuntando que del mismo modo que en la antigua Grecia se denominaba a la poesía "danza parlante" ${ }^{68}$ hemos denominado aquí a la danza poesía corporal ya que defendemos que la danza es en último término, al igual que la poesía, una metáfora de lo que es el ser humano que ejecuta ese arte; y "eso que es" se refleja en buena medida en su actitud. En la poesía o danza parlante crear un baile con las palabras implica combinarlas y jugar con ellas de modo que el significado final elaborado sea distinto al de la mera unión de esas palabras; y en la danza o poesía corporal defendemos que pasa lo mismo, elaboramos con la suma de movimientos corporales un mensaje que, in extremis, es distinto del que sugiere la suma de esos movimientos analizados por separado.

\section{Bibliografía}

AGUIRRE, J. Ma ., ¿Conoces a estos filósofos? Estudios de filosofía contemporánea. Madrid, Síntesis, 2015.

AGUIRRE, J. Mª., Ética y emancipación. Exploraciones filosóficas. Barcelona, Anthropos, 2015.

AGUIRRE, J. Ma. (ed.), "Ética, mundialización y emancipación", Retos y perspectivas de la filosofía para el siglo XXI. Barcelona-Logroño, Anthropos-Universidad de La Rioja, 2014, pp. 199-219.

ARCHIVES INTERNATIONALES DE LA DANSE de París. Disponible en: http://www.cnd.fr.

BAXMANN, I., "The body as an archive", Knowledge in Motion..., pp. 207-215. BERMEJO, D. (ed.), "Estetización epistemológica", En las fronteras de la ciencia. Barcelona - Logroño, Anthropos - Universidad de La Rioja, pp. 51-82.

BLÄSING, B., "The dancer's memory. Expertise and cognitive structures in dance" $^{\prime \prime}$ The Neurocognition of Dance..., pp. 75-98.

CHAIKLIN, SH., "Hemos danzado desde que pusimos nuestros pies en la tierra", La vida es danza..., pp. 27-37.

67. Morenilla, C., "La danza y su presencia en el programa escolar en la Grecia clásica", II Jornadas de Danza e Investigación (...), pp. 90100.

68. Gentili, B., Poesía y público en la Grecia antigua. Barcelona, Quaderns Crema, 1996, p. 59 . 
CLARK, A., Being there. Putting brain, body and world together again. Cambridge (Massachusetts), The MIT Press, 1996.

CLARK, A., "Incorporización y la Filosofía de la Mente", Contrastes Revista Internacional de Filosofía. Supl. VI 2001, Málaga, 2001, p. 26.

DUNCAN, I., "Terpsícore", Isadora Duncan. El arte de la danza..., pp. 94-96. Original de 1909.

DUNCAN, I., "El teatro griego", Isadora Duncan. El arte de la danza..., pp. 112120. Original de 1915.

DUNCAN, I., "Cómo debería ser la danza", Isadora Duncan. El arte de la danza..., pp. 74-77. Original de 1905-1906.

FISCHMAN, D., "Relación terapéutica y empatía kinestésica", La vida es danza..., pp. 81-96.

FETZ, D. y LANDERS, D., "The Effects of Mental Practice on Motor Skill Learning and Performance: A Meta-Analysis", Journal of Sport Psychology. № 5 , 1983, pp. 25-57.

GADAMER, H. G., Verdad y método: Fundamentos de una hermenéutica filosófica, Salamanca, Sígueme, 1988.

GAGGIOLI, A., MORGANTI, L., MONDONI, M. y ANTONIETTI, A., "Benefits of Combined Mental and Physical Training in Learning a Complex Motor Skill in Basketball", Psychology. No 4, 2013, pp. 1-6.

GALLAGHER, SH., How the Body Shapes the Mind. Oxford, Oxford University Press, 2005.

GEHM, S., HUSEMANN, P. y VON WILCKE, K. (eds.), Knowledge in Motion: Perspectives of Artistic and Scientific Research in Dance. Bielefeld, transcript Verlag (German Federal Cultural Foundation), 2007.

GENTILI, B., Poesía y público en la Grecia antigua. Barcelona, Quaderns Crema, 1996.

GONZÁlEZ, M. A., El arte develado. Consideraciones estéticas sobre la hermenéutica de Gadamer. México, Herder, 2005.

HARVEY, J., Música e inspiración. Barcelona, Global Rhythm Press, 2008.

HEIDEGGER, M., Ser y tiempo. Madrid, Trotta, 2003.

JOLA, C., "Research and choreography: Merging dance and cognitive neuroscience", The Neurocognition of Dance..., pp. 203-234.

KOSELLECK, R., Futuro Pasado. Para una semántica de los tiempos históricos. Barcelona, Paidós, 1993.

MARKESSINIS, A., Historia de la danza desde sus orígenes. L. D. Esteban Sanz Martier, Madrid, 1995.

MERLO, V., Filosofía, ¿qué es eso? Saber y ser en Occidente y Oriente. Madrid, Biblioteca Nueva, 2014.

MORENILLA, C., "La danza y su presencia en el programa escolar en la Grecia clásica", Il Jornadas de Danza e Investigación. (...). Barcelona, Los Libros de Danza, 2000, pp. 90-100. 
PUTTKE, M., "Learning to dance means learning to think!", The Neurocognition of Dance..., pp. 101-114.

SACHS, C., Historia Universal de la Danza. Buenos Aires, Centurión, 1944.

SÁNCHEZ, J. A., Isadora Duncan. El arte de la danza y otros escritos. Madrid, Akal, 2008.

SERVOS, N., "What the body remembers", Knowledge in Motion..., pp. 185-206.

TRÍAS, E., "El criterio estético", Creaciones Filosóficas I. Ética y estética. BarceIona, Galaxia Gutenberg-Círculo de Lectores, 2009, pp. 345-370. Original de 1997.

TRÍAS, E., "Estética del límite", Creaciones Filosóficas I..., pp. 211-344. El original pertenece a Lógica del límite, 1991.

TRÍAS, E., La edad del espíritu. Barcelona, Destino, 1994.

TRÍAS, E., "Lo bello y lo siniestro", Creaciones filosóficas I..., pp. 91-208. Original de 1982.

TRÍAS, E., Los límites del mundo. Barcelona, Destino, 2000.

VÖLCKERS, H., "Preface", Knowledge in Motion..., pp. 9-14.

WENGROWER, H. y CHAIKLIN, SH. (coords.), La vida es danza. El arte y la ciencia de la Danza Movimiento Terapia. Barcelona, Gedisa, 2008.

WENGROWER, H., "El proceso creativo y la actividad artística por medio de la danza y el movimiento", La vida es danza..., pp. 39-57. 